
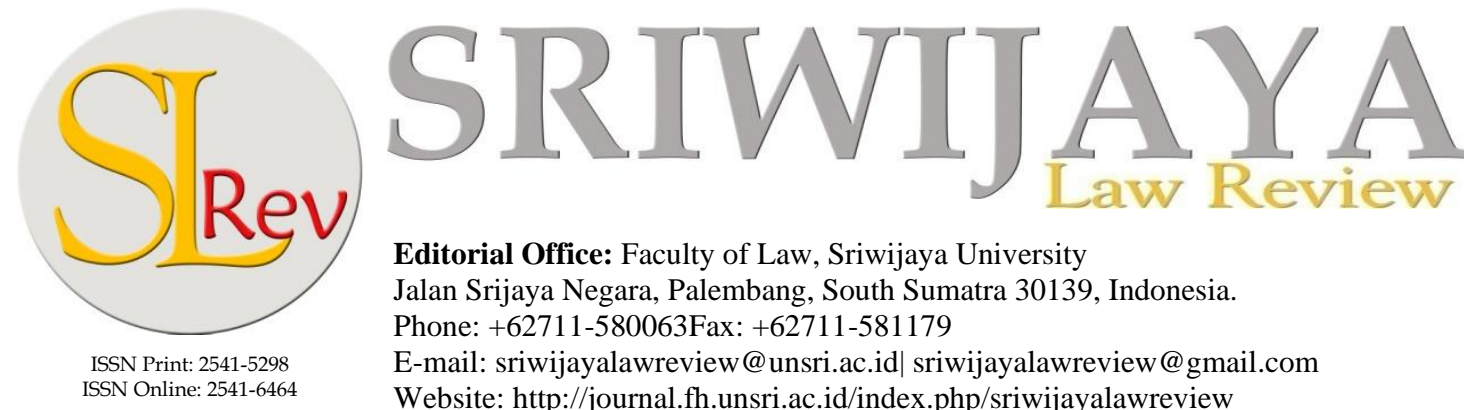

Editorial Office: Faculty of Law, Sriwijaya University

Jalan Srijaya Negara, Palembang, South Sumatra 30139, Indonesia.

Phone: +62711-580063Fax: +62711-581179

E-mail: sriwijayalawreview@unsri.ac.id|sriwijayalawreview@gmail.com

Website: http://journal.fh.unsri.ac.id/index.php/sriwijayalawreview

\title{
Society 5.0: A New Challenge to Legal Norms
}

\author{
Nabeel Mahdi Althabhawi, ${ }^{\mathrm{a} *}$ Zinatul Ashiqin Zainol, ${ }^{\mathrm{a}}$ Parviz Bagheri ${ }^{\mathrm{b}}$
}

a Faculty of Law, Universiti Kebangsaan Malaysia (UKM), Malaysia. Corresponding Author Nabeel Mahdi Althabhawi,email: althabhawi@ukm.edu.my

b Department of Law, Ilam University, Iran.

\begin{tabular}{|c|c|}
\hline Article & Abstract \\
\hline $\begin{array}{l}\text { Keywords: } \\
\text { Intellectual property; } \\
\text { Internet of things; Smart } \\
\text { Contracts; Society 5.0; } \\
\text { Privacy. } \\
\text { Article History } \\
\text { Received: Sep 12, 2021; } \\
\text { Reviewed: Jan 6, 2021; } \\
\text { Accepted: Jan 24, 2022; } \\
\text { Published: Jan 31, 2022. } \\
\text { DOI: } \\
\text { 10.28946/slrev.Vol6.Iss1. } \\
\text { 1415.pp41-54 }\end{array}$ & $\begin{array}{l}\text { Society } 5.0 \text { is a new term used to indicate the future world. This society is } \\
\text { based on ubiquity, learning machines, the internet of things, big data, cloud } \\
\text { computing, cryptography, and biometrics. All these technologies will be } \\
\text { merged to create a new mode of life. The new way of life will inevitably in- } \\
\text { fluence human beings' values, concepts, and conduct. The result of these } \\
\text { changes will consequently bring challenges to many legal areas. This paper } \\
\text { addresses the challenges that brought society } 5.0 \text { to legal norms. It utilises } \\
\text { the analytical approach to examine the capability of pre-existing legal norms } \\
\text { to cope with new realities created by society } 5.0 \text {. The paper analyses the } \\
\text { legal implications of society } 5.0 \text { in their sociological context. It presents a } \\
\text { jurisprudential vision to establish legal norms compatible with the new } \\
\text { society. Three fundamental principles should be considered to establish new } \\
\text { legal. First, social facts that trigger legal regulation can simultaneously occur } \\
\text { in multiple places. Secondly, what the study called duality of legal rules will } \\
\text { not survive in society } 5.0 \text { era. Third, the paper turns the spotlight on new } \\
\text { intelligent systems which may introduce new law addressees. }\end{array}$ \\
\hline
\end{tabular}

\section{INTRODUCTION}

Society 5.0 is a Japanese term that was introduced in the Fifth Basic Plan ${ }^{1}$ by the Council for Science, Technology, and Innovation (CSTI) and approved by Cabinet decision in January 2016. In the Fifth Basic Plan, Society 5.0 is defined as follows:

"A society that is capable of providing the necessary goods and services to the people who need them at the required time and in just the right amount; a society that is able to respond precisely to a wide variety

1 The fifth plan is the last of the five plans regarding science and technology, and every plan spent five years since 1996. The fifth plan is scheduled for 2016-2020 Slavko Arsovski, "Quality Of Life And Society 5.0," 2020, http://www.cqm.rs/2019/papers_iqc/81.pdf. 
of social needs; a society in which all kinds of people can readily obtain high-quality services, overcome differences of age, gender, religion, and language, and live vigorous and comfortable lives". ${ }^{2}$

The term was coined according to human history. The history of humanity was divided into five periods. The classification was based on the most popular way of resource procurement. Society 1.0 was hunt-based. Therein people used to gather their resources from the natural environment. Society 2.0 was an agriculture-based society where the people used to depend on the plantation as a source of living which necessitated a more organised society. Industry characterised society 3.0 as a main economic activity that introduced products to markets. Society 4.0 was an information-centralised society with more intellectual values. Society 5.0 is aimed to be a human-centred society. ${ }^{3}$ Society 5.0 reflects the view of a supersmart society that is seen to be incept in $2025 .{ }^{4}$ The term has its counterparts across industrial nations. The most popular equivalent is the term "Industry 4.0", which a Europe-originated reflects the "4th Industrial Revolution". "Made in China 2025" is another Asian policy that the Chinese government launched.

Some literature, however, tried to draw a distinguishing line between society 5.0 and industry 4.0. Speaking lexically, it is apparent that the term industry 4.0 is technology-focused, whereas the term society 5.0 is designed to put humans in the centre of attention. ${ }^{5}$ Nonetheless, it is asserted that the term is very related. Society 5.0 will aim to reach an entire interaction between humans and machines whose optimisation is the core of industry 4.0. ${ }^{6}$ Society 5.0 initiative prioritises social problems by creating novel values by utilising a broad spectrum of systems and technologies. The Japanese vision is to create a new, human-centred society that resolves diverse societal problems. ${ }^{7}$

The future long-term perspective is a super-smart society. Therein big data analysis technologies artificial intelligence technologies are utilised. ${ }^{8}$ Cyber-Physical Systems (CPS) with the Internet of Things (IoT), big data technologies, and artificial intelligence (AI) will be elements of everybody's life. High-priority applications are in the health sector, transportation and mobility, infrastructure maintenance, and the financial sector". 9

Ubiquity will be the most dominant feature of goods and services in society 5.0. They will be available "to anybody at any time and at any place regardless of region, age, gender,

2 Cabinet Office the Government of Japan, Society , http://www8.cao.go.jp/cstp/english/basic/5thbasicplan.pdf.

3 Mayumi Fukuyama, "Society 5.0: Aiming for a New Human-Centered Society," Japan SPOTLIGHT, 2018.

4 Arsovski, "Quality Of Life And Society 5.0."

5 Carlos Miguel Ferreira and Sandro Serpa, "Society 5. 0 and Social Development," Preprints, 2018, https://doi.org/10.20944/preprints201811.0108.v1.

6 Bruno Ratti, "Geographic Knowledge. Paradigm of Society 5.0," Copyright@ Nuova Cultura Italian Association of Geography Teachers Journal of Research and Didactics in Geography (J-READING, 2018, https://doi.org/10.4458/0623-08.

7 Fukuyama, "Society 5.0: Aiming for a New Human-Centered Society."

8 Hisanori Hayashi et al., "International Standardization for Smarter Society in the Field of Measurement, Control and Automation," in 2017 56th Annual Conference of the Society of Instrument and Control Engineers of Japan, SICE 2017, 2017, https://doi.org/10.23919/SICE.2017.8105723.

9 Dimitrios Serpanos, "The Cyber-Physical Systems Revolution,” Computer, 2018, https://doi.org/10.1109/MC.2018.1731058. 
language or other limitation"10 This will be achievable by connecting everything in a worldwide network. Internet of things (IoT) will ease life by rendering everything working connectedly. IoT will bring many legal challenges to pre-existing legal systems. ${ }^{11}$ There is an urgent need to regulate IoT to address all these challenges. ${ }^{12}$ The use of IoT will create a massive amount of data (big data) that will be created, stored, and analysed. Big data technologies will be deemed a new significant production management element in society 5.0. ${ }^{13}$ In combination with big data, cloud computing, which is remote access to data, programs, and browsers, will be a crucial element of society 5.0. ${ }^{14}$ Autonomous robots will be one of the most influential features in society 5.0. They will respond to the surrounding environment after sensing it and processing information cognitively. ${ }^{15}$

Despite being Japanese-introduced, society 5.0 will potentially affect people worldwide. Its challenges will confront the rest of the world. Consequently, the solutions to the problems of society 5.0 will have to be shared worldwide. ${ }^{16}$ The legal reaction is a consequence of social changes. New social facts often bring new laws. In the coming sections, this paper will address the most significant legal issues surrounding the emergence of society 5.0. First, it will outline the forthcoming globality and how it could undermine cultural and legal boundaries. Secondly, the study will go to the dichotomy of the real-virtual world. The article will address the implication of society 5.0 on the distinctions between the real world and the virtual world. The third issue that will be elaborated on is data regulation in the age of society 5.0. As aforementioned, a considerable amount of data will be available in society 5.0. This availability will bring the issue of data ownership. The fourth issue will be the security of society 5.0 as cyber activities will be the cornerstone of this world. The fifth part of the examination will be the contract law and how it will cope with the new wave of smart cognitive machines. In the end, the study will present a jurisprudential vision to establish compatible solutions to problems accompanying society 5.0.

\section{RESEARCH METHODS}

The research adopted a normative analytical methodology to outline the legal principles and doctrines that may be applicable to society's new realities brought by society 5.0. As doctrinal research, the study went through secondary materials which touch legal aspects of Society 5.0. Multiple databases were utilised, e.g., CLJ, LawNet, Lexis Legal Research for Academic, and HeinOnline. Simultaneously, the study conducted a legal analysis of collected data. By this analytical method, the study identified obstacles facing the applicability of the current legal

10 Arsovski, "Quality Of Life And Society 5.0."

11 "Legal Perspectives on the Internet of Things," Conferinta Internationala de Drept, Studii Europene Si Relatii Internationale, n.d., 523-32.

12 Kateryna Nekit, Denis Kolodin, and Valentyn Fedorov, "Personal Data Protection and Liability for Damage in the Field of the Internet of Things," Juridical Tribune 10 (2020): 80-93.

13 Ayșe Göksu Özüdoğru, Esra Ergün, and Djihane Ammari, "How Industry 4.0 Changes Business: A Commercial Perspective," International Journal of Commerce and Finance, 2018.

14 Herbert B. Dixon, "Cloud Computing," Judges Journal 51, no. 2 (2012): 36.

15 Özüdoğru, Ergün, and Ammari, "How Industry 4.0 Changes Business: A Commercial Perspective."

16 Asta Savanevičienè, Gita Statnickè, and Sigitas Vaitkevičius, "Individual Innovativeness of Different Generations in the Context of the Forthcoming Society 5.0 in Lithuania," Engineering Economics, 2019, https://doi.org/10.5755/j01.ee.30.2.22760. 
system to new realities in society 5.0 and examined them in a sociological context. The result of this doctrinal were three essential jurisprudential foundations thereupon the new legal system should be based.

\section{ANALYSIS AND DISCUSSION \\ Borderless World}

Since the inception of the internet in the 1970s, geography-based disciplines have struggled to cope with the unique ability of the network to have people interact, notwithstanding their places. Law has been in the heart of this frontline. Boundaries determine legal jurisdictions. Thereon the most challenging value, "national sovereignty," is relied upon. It is a well-known fact that borders are not just lines between the territories of two states. For law, borders represent a demarcation line between two jurisdictions. Each of them is solely applicable to one side of the borders. The sovereignty of a nation cannot be extended out of its borders. In cyberspace, there are no physical borders. Events in cyberspace do not need a geographical location to occur. Geographical location is a ground for two factors of legal regulation; the power of governments the implication of the behaviour. ${ }^{17}$ Governments practice their power in geographical-limited atmospheres. Furthermore, behaviour impacts have to be regulated by the law applicable in the place of action.

Two immediate solutions have been evolved to have place-based principles and rules survive. There was a holding that cyberspace is out of geographical nature. It is available to all whenever and wherever. This was apparent in the American case of Reno v. American Civil Liberties Union. ${ }^{18}$ Another stance asserted that the internet creates its geography. ${ }^{19}$ However, this direction did not state which jurisdiction is applicable in this geography.

Whatever the proper comprises to internet-geography theoretical conflict, we seem to have more controversy on this issue from its socio-legal horizon. Society 5.0 and its newbrought technologies will lead to a significant social change. ${ }^{20}$ It will profoundly intervene in the very private life of everybody. With the decay of influence of poor and small nations in the technology-based world, giant industries will mainly lead the type and extent of technology.

Although local markets will draw a part of the picture, it is ostensible that these markets will be built according to laypeople, which generally prefer ease and price to other factors. National legal principles and rules based on ethnic, cultural, and religious particularities will confront the new age of change. The deterioration of local identities will be one of the biggest challenges in the society 5.0 era. To confront this perplexing issue, it is more appropriate to preventive steps rather than to solve problems. Combining society 5.0 technologies with national identities will be the proper response to the forthcoming era. However, this solution will necessitate the enhancement of local technological industries to keep pace in the new age of technology.

17 David R. Johnson and David Post, "Law and Borders - The Rise of Law in Cyberspace," Stanford Law Review, 1996, https://doi.org/10.5210/fm.v1i1.468.

18521 U.S. 844, 117 S. Ct. 2329, 138 L. Ed. 2d 874 (1997).at 851.

19 Ryan Calo, "Robotics and the Lessons of Cyberlaw,” California Law Review, 2015.

20 Savanevičienè, Statnickè, and Vaitkevičius, "Individual Innovativeness of Different Generations in the Context of the Forthcoming Society 5.0 in Lithuania." 
Small countries with non-Western ${ }^{21}$ cultures and relatively limited technological capability will have to meet the challenge. The negligence of this fact may lead to the emergence of a new sort of social-isolated extremism.

\section{Data Regulation}

In January 2019, During the World Economic Forum in Davos, the Japanese Prime Minister addressed the significance of data in society 5.0: "it is no longer capital but data that connects and drives everything". A considerable amount of data will be created in society 5.0.22 Furthermore, they will have to be collected and analysed. For instance, smart cars will collect data about traffic, routes, and transportation conditions. Smart-household devices will have to obtain data related to the food, clothes, movements, and health conditions of people living in $^{23}$. Big data technology will be one of the essentials of society 5.0. New database software will be responsible for capturing, storing, managing, and analysing data. ${ }^{24}$

The study opines that the significant inquiry will no longer be protecting this data in the privacy law context. Privacy law is a violation-driven law. The main goal is to protect data from being infringed by others. This policy will not survive in Society 5.0, and data regulations should be exploitation driven. The prospective society 5.0-data will be of economic value, which requires different laws. Instead, the significant issue will be who will have erga omnes right to use this big data. The traditional legal framework will not fit the purpose in society 5.0 life. Multiple parties will seek to own data. Owners of devices, users, manufacturers, internet providers, third parties like traffic authorities, and insurance companies will also be players in the data ownership competition. ${ }^{25}$ The approach of claiming data ownership relying on generations of data by the parties involved will not fit the purpose in society 5.0. It was argued that data ownership should be based on another ground. The value of data may come from its relation to individuals like guests who might participate in data generation for a short time. ${ }^{26}$ Consequently, data ownership should be based on the relevance of data to individuals rather than their involvement in data generation.

21 The non-western world refers to the areas in which cultures developed essentially apart from the Greco-JudaicChristian tradition of the Western culture. See Cinad P. Karan Pradyumna, "The Non-Western World," The Non-Western World: Environment, Development and Human Rights, September 2004, 1-589, https://doi.org/10.4324/9780203331255.

22 In 2013, it was said that $90 \%$ of 2013-world's data had been created in the previous two years, 2.5 quintillion bytes of data every day. See IBM, "2.5 Quintillion Bytes of Data Created Every Day. How Does CPG \& Retail Manage It?" 2019, https://www.ibm.com/blogs/insights-on-business/consumer-products/2-5-quintillion-bytesof-data-created-every-day-how-does-cpg-retail-manage-it/.

23 Seung Woo Kum, Mingoo Kang, and Jong Il Park, "Iot Delegate: Smart Home Framework for Heterogeneous Iot Service Collaboration," KSII Transactions on Internet and Information Systems 10, no. 8 (August 2016): 3958-71, https://doi.org/10.3837/tiis.2016.08.029.

24 Özüdoğru, Ergün, and Ammari, "How Industry 4.0 Changes Business: A Commercial Perspective."

25 Thomas J. Farkas, "Data Created by the Internet of Things: The New Gold without Ownership?," Revista La Propiedad Inmaterial, 2017, https://doi.org/10.18601/16571959.n23.01.

26 Brendan Alan and Melander, "Smart Stadiums: An Illustration of How the Internet of Things Is Revolutionising the World," Sports \& Entertainment Law Journal 6, no. 2 (2017): 349-82. 
A commentator examined the pertinence of the types of IP rights protection from the data ownership perspective. He concluded that no pre-existing system is satisfactory. ${ }^{27}$ Copyright cannot be the appropriate option to regulate data ownership. First, most copyright subject matters are linked with the world of literature, writing, and authorship. Second, the scope of copyright protection is not pertinent to society 5.0 data. Data value is derived from its content rather than its form. If data is copyrighted, other forms of its contents will be unprotected. Moreover, it was asserted that sui generis is not the relevant tool to protect data ownership. ${ }^{28}$ The European Database Directive requires that data and materials are organised systemically. Moreover, they have to be individually accessible. ${ }^{29}$ Additionally, the directive protects "seeking out and collecting existing independent materials and collecting them in a database. It does not protect investment in the creation of data" ${ }^{30}$ Although the study agrees that sui generis will not be sufficient to protect society 5.0 data, it takes an issue with the discrimination between data creation and data collection. First, data is collected information, and it is apparent that the creation and collection processes are parallel. Secondly, there are some cases of ruling flaws in the face of this kind of discrimination relying on the intention of drafters of the directive. ${ }^{31}$ Farkas ${ }^{32}$ argued that the privacy of legal data framework is not also pertinent to protect data ownership as it is confined to a particular sort of data. Furthermore, the remedies which are given in the case of data contravention are very restricted. He proposed a new sort of IP rights to regulate data ownership as a sequence. The subject matter for the new right will not be every data created and collected. The proposal suggests another requirement which is called "novelty" or "added value". The new right holder will be the party with "most interest". 33

Another proposal to establish a new form of intellectual property rights relies on the differentiation between personal data protected under privacy laws and the society 5.0-data "synthetic information" instead of limiting the scope of data protected by the new form. This proposal widens the scope of information to cover a vast range of machine-readable information. ${ }^{34}$

Despite our acceptance of the fact that traditional IP legal framework will not be sufficient or at least efficient to regulate the ownership of data in society 5.0, the study is at the view that establishing new sorts of IP rights for every new wave of intangible assets will lead to asymmetry of the theory of intellectual property. Instead, the paper argues that IoT and the other essentials of society 5.0 will take us to the convergence point of the real-world and virtual

Farkas, "Data Created by the Internet of Things: The New Gold without Ownership?"

Farkas.

9 Article 1 (2).

30 British Horseracing Board v William Hill Computer Law \& Secirity Report, Vol 20, Issue 5, SeptemberOctober 2004.

31 Football Dataco v Sportradar [2103] EWAC Civ 27 at Para 60.

32 Farkas, "Data Created by the Internet of Things: The New Gold without Ownership?"

33 Farkas.

34 Christoph Krönke, "Data Regulation in the Internet of Things," Frontiers of Law in China (Brill Academic Publishers, October 2018), https://doi.org/10.3868/s050-007-018-0028-9. 
world. The dichotomy of real-virtual is at the hazard of disappearing. Even if that looks like a far future, ${ }^{35}$ it should be put in our minds that it is an inevitable future.

\section{Virtual versus Real}

As mentioned earlier, cyberspace has been a perplexing issue for law. As this space is not tangible, the solution was to deem it and all its occupiers as virtual. The virtual-real dichotomy was a dividing line between the pre-internet realities and post-internet realities. IT researchers have worked to bridge the gap. Eventually, the advancement of technology has come with a sort of convergence between real and virtual worlds by what is called virtual reality (VR). VR replaces the sense of the real world with a virtual sense of another world. It allows people to put themselves inside a virtual space which is deemed as virtual reality. ${ }^{36}$

Another improvement has come with more than putting people inside VR. Augmented reality (AR) is one of the new game-change factors in society 5.0. Interestingly, Pokemon GO was the first example of augmented reality (AR). ${ }^{37}$ Augmented reality is a technology that brings virtual objects into the real world, and the fascinating end will be a virtual real mixed world. ${ }^{38}$ Using smartphones, digital 3D objects will be seen inside the real world. ${ }^{39}$

VR and AR have started with the game and cartoon industries. However, the forthcoming additions will be avatars. These cartoon beings will be connected with us as our reflections. This will bring the issue of the physical existence and the place of conduct. Thereupon, jurisdiction will be determined. VR and AR will affect the way how people interact with each other. ${ }^{40}$ Consequently, the law will need to address a new dimension of social relationships.

There is no clear expectation of what the legal challenges will accompany AR. Lemley \& Volokh, however, addressed some legal issues that have to be examined in the AR context. First, the consent of people to activities involving them may be shifted when it turns from environment to environment. Secondly, intellectual property rights will be at the centre of this controversy. Ownership and protection for 3D-beings avatars have to be addressed in detail. ${ }^{41}$ Third, the issue of the crimes committed in augmented reality society needs to be addressed. One might take an issue with the occurrence of crimes in AR. It can be said that there are four levels of human interaction. Each of them has a particular type of crime, textual, aural, visual, and haptic. The problem is that the level of interaction in AR will be enhanced to be visionbased interaction. Criminal offences could be directed to the original being and then governed by the traditional rules or criminal laws. But what is the applicable law where the criminal attack is directed to AR-beings of the physical objects or humans? What is the legal attitude if VR and AR were merged? Finally, tort law will be at the spotlights, using AR to make "false factual assertions that injure the avatar's reputation and thus make it harder for a person to

35 Krönke.

36 Mark A. Lemley and Eugene Volokh, "Law, Virtual Reality, and Augmented Reality," University of Pennsylvania Law Review, 2018, https://doi.org/10.1016/b978-0-08-102253-5.00007-1.

37 Lemley and Volokh.

38 Özüdoğru, Ergün, and Ammari, "How Industry 4.0 Changes Business: A Commercial Perspective."

39 Lemley and Volokh, "Law, Virtual Reality, and Augmented Reality."

40 Lemley and Volokh.

41 Lemley and Volokh. 
engage in business and social life using the avatar should be a tort, even if the avatar is pseudonymous". 42

\section{Security of Society 5.0}

It is undeniable that security risks will ensue as a result of more excellent connectivity in society 5.0. The current security technologies are unsatisfactory in society's age of society 5.0 as they "involve the data fusion of four-dimensional spaces; Worse, existing technologies cannot counter the threats for BCI when the thinking space is highly fused with the other threedimensional space; This situation provides multiple sources at which hackers can attack the systems. Hence, the aspects of security and privacy are expected to be concerned" ${ }^{43}$ The security management in society 5.0 will be a foreseen challenge, especially with the increase of cyber-attacks against industries. ${ }^{44}$ The absence of a straightforward way to alert users when cyber-attacks occur may pave the way for continuous attacks without detection. ${ }^{45}$ Evolving concepts of cybersecurity laws remain challenged by the rapid pace of technology development. ${ }^{46}$ Society 5.0 will likely deepen the gap between legal regulations of security and technological advancements.

The study argues that cyber-attacks in society 5.0 will be more hazardous than their counterpart in society 4.0. First, a massive amount of data will be controllable by hackers. Attacking storage of big data will affect more people with more information hacked. Secondly, the target will be internet-connected objects that collaborate with other objects; hence hacking one object will affect the whole set of connected devices. Third and more significant, the decentralisation nature of society 5.0 may render hackers capable of invading secure objects seizing the lack of coordination between the leading players of society 5.0.

Asian countries will face a complex challenge in this context. It was asserted that Asian governments' regulations and standards are currently lacking. There is no sufficient awareness among consumers to demand privacy and security solutions. ${ }^{47}$ Furthermore, there is a noncompliance between technological development and legal security rules in the region.

\section{Smart Contracts and Cryptocurrency}

It can be asserted that contract law will be one of the most legal sub-disciplines touched by society 5.0. The emergence of smart contracts and cryptocurrency is changing two elements of contracts; mechanism and subject matters. A smart contract is defined as "a set of promises,

42 Lemley and Volokh.

43 Hong Liu et al., "A Review of the Smart World," Future Generation Computer Systems, 2019, https://doi.org/10.1016/j.future.2017.09.010.

44 Mauricio Paez and Kerianne Tobitsch, "The Industrial Internet of Things: Risks, Liabilities, and Emerging Legal Issues," New York Law School Law Review 62 (2017).

45 Scott J. Shackelford and Scott Russell, "Above the Cloud: Enhancing Cybersecurity in the Aerospace Sector," FIU Law Review 10, no. 2 (January 2015), https://doi.org/10.25148/lawrev.10.2.16.

46 Lawrence J. Trautman, "Industrial Cyber Vulnerabilities: Lessons from Stuxnet and the Internet of Things," SSRN Electronic Journal, 2017, https://doi.org/10.2139/ssrn.2982629.

47 Internet of Things, issues paper, Asia pacific bureau of internet society, 2017, p 3 
including protocols within which the parties perform other promises." ${ }^{48}$ Smart contracts are mainly self-executed rely on codes that were designed according to pre-determined conditions. ${ }^{49}$ Smart contracts are drafted in the form of codes instead of human language. ${ }^{50}$ The codes are not responsible for concluding the contract solely. Their role is extended to the contract performance. ${ }^{51}$ The software will determine the conclusion and execution of contracts. ${ }^{52}$ Consequently, the contractual drafting will be at a low cost. ${ }^{53}$ Additionally, contract breach is inconceivable in smart contracts. ${ }^{54}$

On the other hand, cryptocurrency is a "digital currency in which encryption techniques are used to regulate the generation of currency units and verify the transfer of funds, and which operate independently of a central bank". 55 The medium of cryptocurrency is called blockchain, a technology record that stores transactions in the form of debits and credits to decentralised accounts. ${ }^{56}$ The most famous example of cryptocurrency is bitcoin, which is stored and transferred via a decentralised computer network. The creation of bitcoin is by solving cryptographic problems. The reward of the solution will be the entitlement to the package of values stored in "blocks". The most revolutionary fact is that bitcoin is uncontrollable by the government and banks ${ }^{57}$. Another famous example of cryptocurrency is called Ether. Ethereum blocks are rapidly created compared with bitcoin blocks. Likewise, they are more linked with smart contracts as they were designed to be part of smart contracts. ${ }^{58}$ Finally, bitcoin is confined to some sorts of smart contracts, whereas there is no limitation of Ethereum smart contracts. ${ }^{59}$

Commentators bring some issues to be addressed when smart contracts come under discussion. The most significant issue is the applicability of the traditional legal framework for smart contracts. Some asserted that smart contracts are no more than new forms of contracts. Others took an issue with that by denying such a stance. ${ }^{60}$ The second issue is that codes may not express the intention of contractual parties. People express their intention by human language, which may differ from what software does. ${ }^{61}$ This vagueness will cast a shadow on contract interpretation. ${ }^{62}$ Third, the inflexibility of smart contracts examines the sufficiency of smart contracts in the case of unforeseen circumstances. ${ }^{63}$ Fourth, there is a suspicion about the

48 Jerry I-H Hsiao, "Smart Contract on the Blockchain-Paradigm Shift for Contract Law," US-China Law Review 14 (2017).

49 Zibin Zheng et al., "An Overview on Smart Contracts: Challenges, Advances and Platforms," Future Generation Computer Systems 105 (April 2020): 475-91, https://doi.org/10.1016/j.future.2019.12.019.

50 Hsiao, "Smart Contract on the Blockchain-Paradigm Shift for Contract Law."

51 Zheng et al., "An Overview on Smart Contracts: Challenges, Advances and Platforms."

52 Morgan Temte, "Blockchain Challenges Traditional Contract Law: Just How Smart Are Smart Contracts?," Wyoming Law Review 19, no. 1 (January 2019).

53 Hsiao, "Smart Contract on the Blockchain-Paradigm Shift for Contract Law."

54 Temte, "Blockchain Challenges Traditional Contract Law: Just How Smart Are Smart Contracts?"

55 Temte.

56 Temte.

57 Adam J Kolber et al., "Not-So-Smart Blockchain Contracts and Artificial Responsibility," n.d.

58 Temte, "Blockchain Challenges Traditional Contract Law: Just How Smart Are Smart Contracts?"

59 Kolber et al., "Not-So-Smart Blockchain Contracts and Artificial Responsibility."

60 Temte, "Blockchain Challenges Traditional Contract Law: Just How Smart Are Smart Contracts?"

61 Hsiao, "Smart Contract on the Blockchain-Paradigm Shift for Contract Law."

62 Temte, "Blockchain Challenges Traditional Contract Law: Just How Smart Are Smart Contracts?"

63 Hsiao, "Smart Contract on the Blockchain-Paradigm Shift for Contract Law." 
applicability of smart contracts for contracts whose subject matters are assets. ${ }^{64}$ Fifth, there is a possibility of illicit practice of law by coders a license. ${ }^{65}$

Whatever the appropriate attitude to these issues, society 5.0 smarter contracts and more virtual currency will be essential parts of our life. Smart contract problems may extend to all contracts to confront the foundations of contract law theories. Artificial intelligence will take a more significant role in society 5.0 with smarter technologies that enable robots to conduct more activity independently without a prior order from humans. Fascinatingly, there are technological advancements that may enable robots to be decision-makers. ${ }^{66}$ From the contract law perspective, contract conclusions are no more than decisions. So, what is the solution if someone deals with a robot to deliver service? This will arguably be the most challenging issue in the society 5.0 era.

\section{Discussion}

In the preceding sections, the paper discussed some legal issues that will potentially accompany society 5.0. It can be argued that these issues will not definitely be the only issue confronting law practitioners. Society 5.0 introduces a new way of life that brings many new issues to the discussion table. Moreover, it is asserted that their solutions are far from maturity. Huge factors will shape solutions to legal issues created by society 5.0 realties.

The study argues that three main jurisprudential problems will face the law in the context of society 5.0. First is the local-global confrontation. Second is the real-virtual duality of the legal rules and principles. The third is the problem of semi-thinking and smart objects. If we come up with solutions to these three foundational problems, we will have a good vision that could shape a legal system that survives in society 5.0.

As mentioned in subsection 2, local sovereignty will face more risk of disappearing or at least decaying. The transitional technological giants will draw the picture of the new society. Undeniably, the economic and commercial facts will be dominant in the new vision of society 5.0. However, local cultures and identities will have to opt for one of two challenging routes, merge or isolation. Both of them are undesirable potentials. Hence it can be asserted that nonWestern nations have to be among the players of society 5.0 by pursuing technological advancement to comply with cultural identity. Society 5.0 should be a multi-cultural society. Otherwise, an identical confrontation will ensue.

Secondly, the real-virtual escalating convergence in society 5.0 will put many legal principles and rules under discussion. Law has responded to the emergence of society 4.0 by a strategy of creating new principles and rules applicable to cyberspace. The study argues that the duality strategy will not be satisfactory in the society 5.0 era. The reality will be reshaped in the everything-connected world. Thus, it is to design principles and rules applicable to the new world of non-border between real and virtual.

Third and most significant, smart objects are taking an increasing role in society. As mentioned, society 5.0 will be a human-machine society with fears of manipulating smart

64 Hsiao.

65 Temte, "Blockchain Challenges Traditional Contract Law: Just How Smart Are Smart Contracts?"

66 Mark A. Lemley and Bryan Casey, "Remedies for Robots," SSRN Electronic Journal, 2018, https://doi.org/10.2139/ssrn.3223621. 
technologies and artificial intelligence. The less educated workforce will encounter an increasing role of the machine in the industrial and even other sectors. ${ }^{67}$ Questions have been introduced about the legal relationship between humans and intelligent machines. ${ }^{68}$ The perplexing fact about future robots is that they are in the middle of the distance between humans and things. ${ }^{69}$ The ability of robots to be algorithm writers will render them making orders instead of executing human orders. ${ }^{70}$ There is a fear of decisions made independently by machines. For instance, it was reported that prosecutors in California had accused a driver of a Tesla autonomous vehicle (AV) of a felony. According to Professor Bryant Walker Smith, this is the first U.S. case in which a severe criminal accusation was filed involving a partially automated driver-assist system. ${ }^{71}$ It was asserted that formulating liability principles applicable to AVs will take longer than estimated because those AV technologies are under development, leading to various unexpected changes. ${ }^{72}$ However, the potential liability could be any of the parties involved in car manufacturing, like automotive manufacturers, fleet operators/service providers, and software manufacturers. ${ }^{73}$ Section 2 in the UK Automated and Electric Vehicles Act 2018 puts liability in the accident therein. AV is involved on the insurer if the car was covered by insurance and on the owner of the vehicle. Nonetheless, it is asserted that there are some restrictions on the damages which are recoverable by this Act. ${ }^{74}$ There are limits on the damages recoverable under the Act. The Act includes restrictions on the property damage that is included within its definition of 'damage' (s.1(3)), excluding damage to (a) the AV itself, (b) goods carried for hire or reward in or on the vehicle or a trailer drawn by it, and (c) property in custody, or under control, of the insured person (where the insurer is liable) or the person in charge of the automated vehicle (where the owner is liable). The quantum of damages payable in respect of property damage in anyone is also limited to the limit of compulsory insurance for property damage. In Malaysia, Road Transport Act 1987 (MRTA) is designed for man-driven cars. In section 2, MRTA defines a driver as a person who drives or is responsible for driving the vehicle. More significant, Section 27 (3) elaborates that a driving licence might be confined to a particular class of vehicles. Section 56 (3) did the same thing regarding public service vehicles. However, all licences are taxonomised according to the drive capability. Consequently, section 41 , which addresses criminal offences in the car accident context, was

67 Paul K. McClure, “'You're Fired,' Says the Robot: The Rise of Automation in the Workplace, Technophobes, and Fears of Unemployment," Social Science Computer Review, 2018, https://doi.org/10.1177/0894439317698637.

68 B. C. Pirvu and C. B. Zamfirescu, "Smart Factory in the Context of 4th Industrial Revolution: Challenges and Opportunities for Romania," in IOP Conference Series: Materials Science and Engineering, 2017 , https://doi.org/10.1088/1757-899X/227/1/012094.

69 Calo, "Robotics and the Lessons of Cyberlaw."

70 Lemley and Casey, "Remedies for Robots."

71 “Tesla Driver Is Charged in a Deadly Crash Involving Autopilot: NPR,” accessed January 19, 2022, https://www.npr.org/2022/01/18/1073857310/tesla-autopilot-crash-charges.

72 H H Hashim and M Z Omar, "Towards Autonomous Vehicle Implementation : Issues and Opportunities," Journal of the Society of Automotive Engineers Malaysia, 2017.

73 Katie Atkinson, “Autonomous Cars : A Driving Force for Change in Motor Liability and Insurance," Atkinson 17, no. 1 (January 2020): 125-51, https://doi.org/10.2966/scrip.170120.125.

74 Ken Oliphant, "Liability for Road Accidents Caused by Driverless Cars," Singapore Comparative Law Review 2019 (2019). 
based on the notion of causation to punish. At the end of the day, the individual-harm causation is not a proper basis for $\mathrm{AV}$ accidents resulting from smart machines wrong or late decisions.

It is apparent for lawyers that logical and intentional decisions with social effect have been solely attributed to humans so far. Law will potentially have to regulate the reaction of these robots as conduct committed by non-legal subjects. The legal theories of juridical persona will not be sufficient to meet this new challenge as they are based on a human being behaving on behalf of juridical persona. The forthcoming generation of robots will have an increasing ability of decision-making. Consequently, law in society 5.0 will have to deal with new nonhuman subjects. The study argues that society 5.0 will consist of a mixed society of men and machines. ${ }^{75}$ Law regulates society by addressing its members. Law addressees have been human so far. The paper argues that legal disciplines will be confronted with actions and decisions taken by non-humans. The pre-existing legal principles will not be satisfactory to meet that challenge.

\section{CONCLUSION}

Society 5.0 is a new game-changer in the legal realm. The foundations of many legal principles and theories have to be revisited and reexamined according to new realities created by the new era. The paper addressed the most significant areas that society 5.0 will potentially touch. The paper found that three main jurisprudential issues will have to be affected. The local-global confrontation will bring the battle of national identities to its peak. Thus, the paper argued that non-Western nations should be part of establishing a multi-cultural world. Secondly, the virtual nature of the world will increase. The information technology revolution pushed the law to create what we can call cyber-rules which apply to cyberspace with the pre-technology rules, which are still applicable to the real world. The paper argued that the duality strategy would not be satisfactory in the society 5.0 era. Lastly, the paper draws attention to non-human decisionmakers who are an essential part of society 5.0 with more cumulative intelligence and cognitive thinking. New law addressee has many different characteristics from humans, creating new rules so sophisticated.

\section{REFERENCES}

Arsovski, Slavko. "Quality Of Life And Society 5.0," 2020. http://www.cqm.rs/2019/papers_iqc/81.pdf.

Atkinson, Katie. "Autonomous Cars: A Driving Force for Change in Motor Liability and Insurance." Atkinson 17, no. 1 (January 2020): 125-51. https://doi.org/10.2966/scrip.170120.125.

Brendan Alan, and Melander. "Smart Stadiums: An Illustration of How the Internet of Things Is Revolutionising the World." Sports \& Entertainment Law Journal 6, no. 2 (2017): 34982.

Cabinet Office the Government of Japan, Society 5.0,

75 Pirvu and Zamfirescu, "Smart Factory in the Context of 4th Industrial Revolution: Challenges and Opportunities for Romania." 
http://www8.cao.go.jp/cstp/english/basic/5thbasicplan.pdf.

Calo, Ryan. "Robotics and the Lessons of Cyberlaw." California Law Review, 2015.

Farkas, Thomas J. "Data Created by the Internet of Things: The New Gold without Ownership?" Revista La Propiedad Inmaterial, 2017. https://doi.org/10.18601/16571959.n23.01.

Ferreira, Carlos Miguel, and Sandro Serpa. "Society 5 . 0 and Social Development." Preprints, 2018. https://doi.org/10.20944/preprints201811.0108.v1.

Fukuyama, Mayumi. "Society 5.0: Aiming for a New Human-Centered Society." Japan Spotlight, 2018.

Hashim, H H, and M Z Omar. "Towards Autonomous Vehicle Implementation: Issues and Opportunities." Journal of the Society of Automotive Engineers Malaysia, 2017.

Hayashi, Hisanori, Hisashi Sasajima, Yoichi Takayanagi, and Hirco Kanamaru. "International Standardization for Smarter Society in the Field of Measurement, Control and Automation." In 2017 56th Annual Conference of the Society of Instrument and Control Engineers of Japan, SICE 2017, 2017. https://doi.org/10.23919/SICE.2017.8105723.

Herbert B. Dixon. “Cloud Computing.” Judges Journal 51, no. 2 (2012): 36.

Hsiao, Jerry I-H. "Smart Contract on the Blockchain-Paradigm Shift for Contract Law." USChina Law Review 14 (2017).

IBM. "2.5 Quintillion Bytes of Data Created Every Day. How Does CPG \& Retail Manage It?," 2019. https://www.ibm.com/blogs/insights-on-business/consumer-products/2-5quintillion-bytes-of-data-created-every-day-how-does-cpg-retail-manage-it/.

Johnson, David R., and David Post. "Law and Borders - The Rise of Law in Cyberspace." Stanford Law Review, 1996. https://doi.org/10.5210/fm.v1i1.468.

Kolber, Adam J, Jonathan Askin, Ryan Calo, David Chalmers, Adam Elga, Daniel Estrada, Drew Hinkes, et al. "Not-So-Smart Blockchain Contracts and Artificial Responsibility," n.d.

Krönke, Christoph. "Data Regulation in the Internet of Things." Frontiers of Law in China. Brill Academic Publishers, October 2018. https://doi.org/10.3868/s050-007-018-0028-9.

Kum, Seung Woo, Mingoo Kang, and Jong Il Park. "Iot Delegate: Smart Home Framework for Heterogeneous Iot Service Collaboration." KSII Transactions on Internet and Information Systems 10, no. 8 (August 2016): 3958-71. https://doi.org/10.3837/tiis.2016.08.029.

"Legal Perspectives on the Internet of Things." Conferinta Internationala de Drept, Studii Europene Si Relatii Internationale, n.d., 523-32.

Lemley, Mark A., and Bryan Casey. "Remedies for Robots." SSRN Electronic Journal, 2018. https://doi.org/10.2139/ssrn.3223621.

Lemley, Mark A., and Eugene Volokh. "Law, Virtual Reality, and Augmented Reality." University of Pennsylvania Law Review, 2018. https://doi.org/10.1016/b978-0-08-1022535.00007-1.

Liu, Hong, Huansheng Ning, Qitao Mu, Yumei Zheng, Jing Zeng, Laurence T. Yang, Runhe Huang, and Jianhua Ma. "A Review of the Smart World." Future Generation Computer Systems, 2019. https://doi.org/10.1016/j.future.2017.09.010. 
McClure, Paul K. "'You're Fired,' Says the Robot: The Rise of Automation in the Workplace, Technophobes, and Fears of Unemployment." Social Science Computer Review, 2018. https://doi.org/10.1177/0894439317698637.

Nekit, Kateryna, Denis Kolodin, and Valentyn Fedorov. "Personal Data Protection and Liability for Damage in the Field of the Internet of Things." Juridical Tribune 10 (2020): 80-93.

Oliphant, Ken. "Liability for Road Accidents Caused by Driverless Cars." Singapore Comparative Law Review 2019 (2019).

Özüdoğru, Ayşe Göksu, Esra Ergün, and Djihane Ammari. "How Industry 4.0 Changes Business: A Commercial Perspective." International Journal of Commerce and Finance, 2018.

Paez, Mauricio, and Kerianne Tobitsch. "The Industrial Internet of Things: Risks, Liabilities, and Emerging Legal Issues.” New York Law School Law Review 62 (2017).

Pirvu, B. C., and C. B. Zamfirescu. "Smart Factory in the Context of 4th Industrial Revolution: Challenges and Opportunities for Romania." In IOP Conference Series: Materials Science and Engineering, 2017. https://doi.org/10.1088/1757-899X/227/1/012094.

Pradyumna, P. Karan. "The Non-Western World." The Non-Western World: Environment, Development and Human Rights, September 2004, 1-589. https://doi.org/10.4324/9780203331255.

Ratti, Bruno. "Geographic Knowledge. Paradigm of Society 5.0." Copyright@ Nuova Cultura Italian Association of Geography Teachers Journal of Research and Didactics in Geography (J-READING, 2018. https://doi.org/10.4458/0623-08.

Savanevičienè, Asta, Gita Statnickè, and Sigitas Vaitkevičius. "Individual Innovativeness of Different Generations in the Context of the Forthcoming Society 5.0 in Lithuania." Engineering Economics, 2019. https://doi.org/10.5755/j01.ee.30.2.22760.

Serpanos, Dimitrios. "The Cyber-Physical Systems Revolution.” Computer, 2018. https://doi.org/10.1109/MC.2018.1731058.

Shackelford, Scott J., and Scott Russell. "Above the Cloud: Enhancing Cybersecurity in the Aerospace Sector." FIU Law Review 10, no. 2 (January 2015). https://doi.org/10.25148/lawrev.10.2.16.

Temte, Morgan. "Blockchain Challenges Traditional Contract Law: Just How Smart Are Smart Contracts?" Wyoming Law Review 19, no. 1 (January 2019).

"Tesla Driver Is Charged in a Deadly Crash Involving Autopilot: NPR," accessed January 19, 2022, https://www.npr.org/2022/01/18/1073857310/tesla-autopilot-crash-charges.

Trautman, Lawrence J. "Industrial Cyber Vulnerabilities: Lessons from Stuxnet and the Internet of Things." SSRN Electronic Journal, 2017. https://doi.org/10.2139/ssrn.2982629.

Zheng, Zibin, Shaoan Xie, Hong Ning Dai, Weili Chen, Xiangping Chen, Jian Weng, and Muhammad Imran. "An Overview on Smart Contracts: Challenges, Advances and Platforms." Future Generation Computer Systems 105 (April 2020): 475-91. https://doi.org/10.1016/j.future.2019.12.019. 